\title{
Analysis of cost between branded medicines and generic medicines in a tertiary care hospital
}

\author{
Mohith N.*, Nalini G. K., Deepak P., Sahana G. N., Jayashree V. Nagaral, \\ Rakshitha B. V., Divyashree C. R.
}

Department of Pharmacology, Hassan Institute of Medical Sciences, Hassan, Karnataka, India

Received: 07 March 2019

Revised: 25 March 2019

Accepted: 03 April 2019

*Correspondence to:

Dr. Mohith N,

Email:

mohith.narasimha@gmail.com

Copyright: () the author(s), publisher and licensee Medip Academy. This is an openaccess article distributed under the terms of the Creative Commons Attribution NonCommercial License, which permits unrestricted noncommercial use, distribution, and reproduction in any medium, provided the original work is properly cited.

\begin{abstract}
Background: There is much debate regarding the importance of promoting the use of cheaper generic alternatives over brand-name drugs. While generic drugs have been noted to be comparable to brand-name drugs in their ability to treat conditions, significant debate surrounding their bioavailability or the concentration of the drug that reaches its site of action has arisen. Many experts continue to believe that generic and brand-name drugs are bioequivalent and equally viable options for effective drug treatment, as assumed in this review.

Methods: Prices of commonly used branded and generic medicines in same concentration, dosage form and combination were compared with the help of Indian Drug Review, brochures of pharmaceuticals and pharmacies and Jan Aushadhi price list 2017. Mean of all the prices available of branded and generic medicine were calculated and the percentage difference in the mean costs of generic and branded medicines were calculated.

Results: The mean cost of 47 branded medicines out of the selected 50 medicines was higher than their generic versions. Mean cost of 3 generic medicines was higher than branded ones. Percentage difference in the mean costs of branded and generic medicines varied from $<10 \%$ to $>70 \%$.

Conclusions: This study has shown a very noteworthy difference of prices between branded and generic drugs. Efforts should be taken to promote the generic medication. Misconception about low efficacy with generic drugs should be erased.
\end{abstract}

Keywords: Branded drugs, Cost-analysis, Debate, Generic drugs, Mean costs, Pharmacoeconomics

\section{INTRODUCTION}

Prescriptions with branded medicines by health professionals is thought to be one of the key causes of the high cost of medicine. The cost incurred by the manufacturer in drug research, production, storage, marketing, and distribution, etc., is directed to the patron. ${ }^{1}$

For same medicine, the difference in cost between branded and generic product varies from $<2$-fold to $>100$-fold. ${ }^{2}$
There are two concepts to be understood here, one is generic vs patented drugs and the other is a drug's "brand name" (proprietary name) versus "non-proprietary name" or generic name. ${ }^{3}$

Branded medicine is the original product that has been developed by a pharmaceutical company. ${ }^{4}$ The company is given exclusive rights of manufacture and distribution of medicine for a certain period of time (patent). During this period, no one else can produce the same drug. 
Generic medicine is a replica of the original branded product, marketed after the patent period or expiry of other exclusive rights and hence supposed to be of low cost. ${ }^{4,5}$

Both branded and generics are manufactured by confirming to international standards.

Generics can be sold by different brand name and may contain different fillers, binders and lubricants which give them a different color, shape, taste, smell, etc. Hence, generic can be marketed under non-proprietary name or as a branded generic. This enables the manufacturer to market the product in a way similar to the proprietary product. ${ }^{6}$

Non-proprietary name is of the active ingredient in the medicine that is determined by an expert committee and is understood internationally. ${ }^{7}$

Prescribing generic drugs means advising drugs manufactured by other companies after expiry of the patent of the parent drug of the innovator company. Very often, it is misconceived as prescribing by a drug's generic name or non-proprietary name. ${ }^{3}$

The unethical promotional practices by the pharmaceutical companies to get more prescriptions from the doctors make the drugs unaffordable to the common man as this adds to the cost of the medicine. ${ }^{8}$

The importance of generic prescribing has been given importance, primarily to reduce the cost of drugs. ${ }^{9}$

With this background a study was planned with the aim to compare the cost of various commonly used branded medicines and generic medicines and to establish the prudence of emphasizing generic versus branded prescription.

\section{METHODS}

An observational study was carried out. Prices of different branded and generic drugs were compared. 50 commonly used drugs available as both branded and generic forms in the same concentration, dosage form, and the combination, belonging to different classes, in HIMS Hassan, Karnataka, India were selected.

Medicines belonging to different classes such as nonsteroidal anti-inflammatory drug, antacids, antihypertensives, anti-diabetics, antibiotics, drugs used for bronchial asthma and cough syrups, etc., were included for comparison. The brand with the highest price and lowest price available were taken into consideration. The comparison between prices were done using Indian Drug Review, brochures of pharmaceuticals and pharmacies and Jan Aushadhi price list 2017. Mean of all the prices available of branded medicine and generic medicine calculated and the percentage difference in the mean costs of generic and branded medicines were calculated.

\section{RESULTS}

A total of 50 medicines were selected for analysis. Of 50 medicines $19,(38 \%)$ branded and generic medicines were having 10\%-40\% difference in their cost.

About 24 (48\%) medicines had 40-80\% difference in their cost and percentage difference $>80 \%$ in $7(14 \%)$ medicines. $47(94 \%)$, branded medicines are costlier than generic drugs and $3(6 \%)$ branded drugs are cheaper than generic drugs.

Mean cost of generic drugs is 13 Rs., whereas branded with highest price is $125 \mathrm{Rs}$., with lowest price is $31 \mathrm{Rs}$.

Percentage difference in the mean costs of branded and generic medicines varied from $<10 \%$ to $>70 \%$.

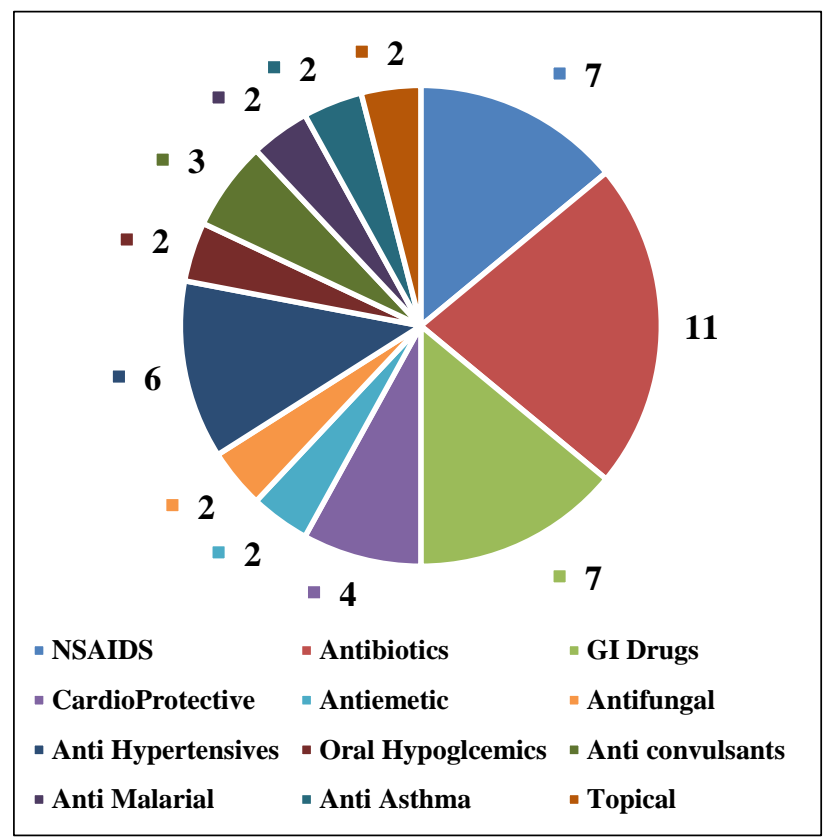

Figure 1: Commonly used branded and generic drugs.

Figure 1 depicts the most commonly used drugs in HIMS Hassan, Karnataka, India and same has been selected for this study. Out of 50 selected drugs 7 (14\%) were NSAIDs, $11(22 \%)$ were antibiotics $7(14 \%)$ were drugs acting on GI tract like anti-diarrhoeal, ulcer protective anti-ulcer drugs, anti-spasmodic so on. 4 (8\%) were cardio protective agents and $6(12 \%)$ were anti-hypertensive, $3(6 \%)$ belonged to anticonvulsant group and $2(4 \%)$ each in antiemetic, Antifungal, oral hypoglycemic agents, anti-malarial, antiasthmatics and topical agents.

Table 1 depicts the number of generic and branded drugs belonging to different price range.

About 34 out of 50 of generic drugs belong between price range of $1-10 \mathrm{Rs}$. and 3 belong to $>50 \mathrm{Rs}$. About 6 of branded drugs with highest price belong to 1-10 Rs group and 22 in $>50$ Rs range. 
Total 19 of branded drugs with lowest price belong to price range between 1-10 Rs and 10 belong to $>50$ Rs.

Table 1: Number and percentage of drugs belonging to different price range.

\begin{tabular}{|lll|l|}
\hline $\begin{array}{l}\text { Price } \\
\text { range }\end{array}$ & Generic & $\begin{array}{l}\text { Branded } \\
\text { (highest price) }\end{array}$ & $\begin{array}{l}\text { Branded } \\
\text { (lowest price) }\end{array}$ \\
\hline $1-10$ & $34(68 \%)$ & $6(12 \%)$ & $19(38 \%)$ \\
\hline $11-20$ & $05(10 \%)$ & $7(14 \%)$ & $8(16 \%)$ \\
\hline $21-30$ & $06(12 \%)$ & $6(12 \%)$ & $9(18 \%)$ \\
\hline $31-40$ & $1(2 \%)$ & $4(8 \%)$ & $2(4 \%)$ \\
\hline $41-50$ & $1(2 \%)$ & $5(10 \%)$ & $2(4 \%)$ \\
\hline$>50$ & $3(6 \%)$ & $22(44 \%)$ & $10(20 \%)$ \\
\hline
\end{tabular}

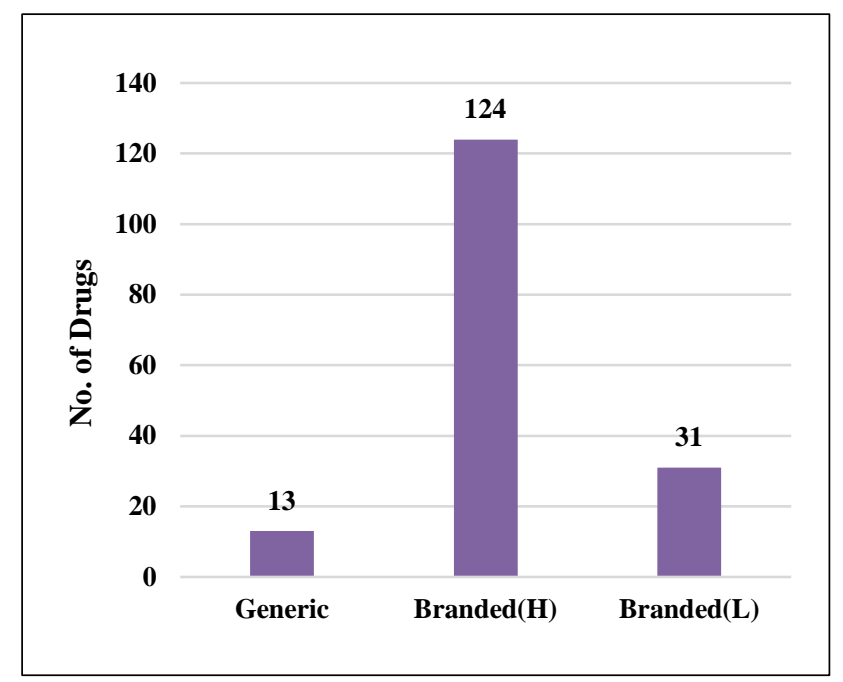

Figure 2: Mean cost (Rs.) of commonly used drugs.

Figure 2 depicts the mean cost of generic vs branded drugs. The mean cost of all the generic drugs came around 13 Rs. whereas the mean cost of branded drugs with highest cost is around $124 \mathrm{Rs}$ and with lowest cost is around $31 \mathrm{Rs}$. The mean cost of generic drugs is cheaper than the mean cost of branded drugs with lowest cost. This implicates that author should prescribe generic drugs in socioeconomically low-class people.

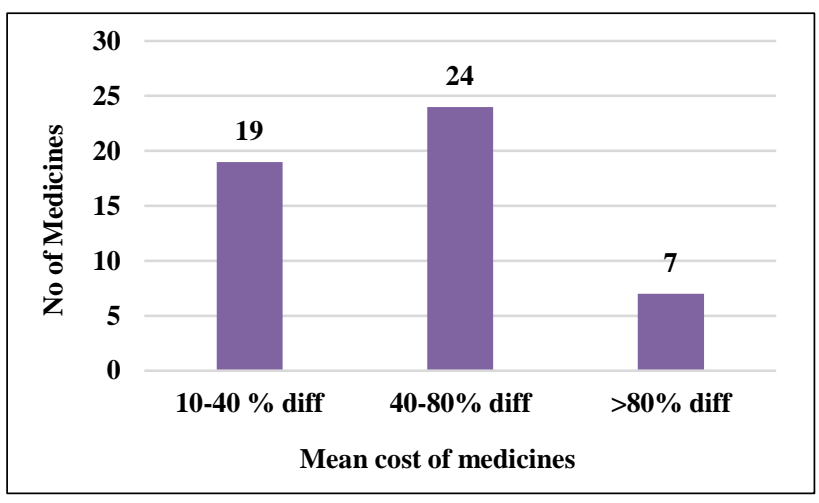

Figure 3: Distribution of total number of medicines according to percentage difference in mean costgeneric vs branded.
Figure 3 depicts the percentage difference in mean cost. out of 50 drugs $19(38 \%)$ have difference of cost between 10$40 \%, 24(48 \%)$ between $40-80 \%$ and $7(14 \%)$ have $>80 \%$.

\section{DISCUSSION}

It is evident by the results after completion of the study that the mean cost of $94 \%$ of branded medicines were found to be more than the mean cost of generic medicines which is consistent with previous findings. ${ }^{10}$

Generic medicines are cheaper in comparison to branded medicines because there is no need to make investments in research and development as in the case of new drugs. $6 \%$ branded medicines were cheaper than the generic medicines. This could be because of prevailing fierce competition among producers makes the manufacturers to keep low prices. ${ }^{11}$

Generic prescribing has been emphasized mainly to reduce the cost of drugs. Until the amendments in the Indian Patent Act in March 2005, India was following process patent system but after becoming a part of the global treaty India has moved to product patent system. ${ }^{12}$

Because of process patents only, in 2002 India was the world's largest producer of generic medicines. ${ }^{12}$

Earlier the branded medicines were manufactured by multinational pharmaceuticals and large Indian pharmaceutical companies and therefore usually expensive. $^{13}$

Practice of bribing doctors for getting more prescriptions is well known which adds to the maximum retail price (MRPs) of the medicines.

Recently, in order to check the doctor-pharmaceutical connection and unethical marketing practices, an authoritative decision dated January 21, 2013 by Medical Council of India which has directed doctors, hospitals, and medical colleges to prescribe by generic names as far as possible as they are thought to be more affordable. ${ }^{9}$

Concern grew about the fate of pharmaceutical industry after the amendment. ${ }^{14}$ There shall be no price hike due to new patent regime. The fear that prices of medicines will spiral is unfounded. ${ }^{15}$

Now the act allows only two types of generic drugs in Indian market: off-patent drugs and generic versions of drugs patented before 1995. Hence, at present nearly $97 \%$ of drugs manufactured in this country are now off patent so Indian pharmaceutical industry will not be affected by product patent regime. ${ }^{16}$

These cover all the lifesaving drugs as well as medicines of daily use for common ailments. ${ }^{14}$ Indian Union Minister for Commerce and Industry, Sri Kamal Nath, assured that "the prices of medicines will not shoot up due to Patents and 
$97 \%$ drugs in the market and $100 \%$ of all essential drugs are not covered by patents." 11,17

Percentage difference in the mean costs of branded and generic medicines varied from $<10 \%$ to $>70 \%$. Actually, almost all the drugs produced in India are generic medicines (generic equivalents) under different brand names. The prices of them may vary and are not controlled by the doctors. MRP is decided and permitted by the government. $^{18}$

Now instead of chasing doctors, pharmaceuticals provide generic medicines to the pharmacies at very cheap rates with MRPs written as allowed by the government, and now these pharmacies have free choice of selling the drug at their own cost.

\section{CONCLUSION}

Facts revealed after the completion of this study are indicative of that the obligation for cost reduction, from the view point of drug selection, lies with the doctors by prescribing the cheapest available drug and include the generic names of the drug in parenthesis, in case that particular brand is not available. The government must make it compulsory for all pharmacies/medical shops to stock generic versions of all essential drugs.

A website/app should be designed and released by the Drug Controller of India which consists of branded drug list so that every doctor can find out cheapest and approved drugs easily.

Funding: No funding sources

Conflict of interest: None declared

Ethical approval: The study was approved by the Institutional Ethics Committee

\section{REFERENCES}

1. Jana S, Mondal P. Pharmacoeconomics: the need to sensitize undergraduate medical students. Ind $\mathrm{J}$ Pharmacol. 2005;37(5):277.

2. Lothium PW, Katzung BG. Basic and Clinical Pharmacology. 12th ed. New Delhi: Tata McGraw Hill; 2012: 1142.

3. Thakkar K, Billa G. The concept of generic drugs and patented drugs vs. brand name drugs and nonproprietary (generic) name drugs. Frontiers Pharmacol. 2013;4:113.

4. Generic medicines and Branded medicines. Available at: http://www.myvmc.com/treatments/generic medicines and branded medicines. Accessed 9 Aug 2017.

5. Generic Drugs, Available at: http://www.who.int/trade/ glossary/story034/en/WHO. Accessed 9 Aug 2017.
6. King DR, Kanavos P. Encouraging the use of generic medicines: implications for transition economies. Croatian Med J. 2002;43(4):462-9.

7. WHO. Guidance on INN, Available at: http://www.who.int/medicines/services/inn/innguidan ce/en/index.html. Accessed 9 August 2017.

8. Singhal GL, Anita K, Arun N. Jan Aushadhi stores in India and quality of medicines therein. Int $\mathrm{J}$ Pharm Pharm Sci. 2011;3(1):204-7.

9. Mukherjee R. Prescribe generic drugs: MCI to doctors, 2013. Available at: https://timesofindia.indiatimes.com/india/PrescribegenericdrugsMCItodoctors/articleshow/18201776.cm s?referral=PM. Accessed 9 August 2017.

10. Gautam CS, Bhanwra S. Pharmacoeconomics: Sensitization of undergraduate medical students. Ind J Pharmacol. 2005;37(5):336-.

11. Dadhich A, Upadhyaya M. A review: exploring branded generic drugs by Indian pharmaceutical multinational companies as a new prospect. Pharmacophore. 2011;2(6):271-5.

12. Product v. Process Patent under Indian Patent Law. Available at: http://www.ssrn.com/abstract $=1758064$ poduct v. Process Patent under Indian Patent Law. Accessed 9 Aug 2017.

13. Ahire K, Shukla MA, Gattani MA, Singh VI, Singh ME. A survey-based study in current scenario of generic and branded medicines. Int J Pharm Pharm Sci. 2013;5(3):705-11.

14. Janodia M, Pandey S, Rao JV, Sreedhar D, Ligade V, Udupa N. Patents regime in India: issues, challenges and opportunities in pharmaceutical sector. Internet $\mathbf{J}$ Third World Med. 2007;7:1.

15. Nath K. Pharma and IT to Benefit, Yojana. March, 2005:49-51.

16. Rohit S, Nilesh LB, Ravikiran KB, Pallavi MC, Pramod VK. The Indian pharmaceutical industry: Evolution of regulatory system and present scenario. Int Res J Pharm. 2012;5(6):49.

17. Janodia MD, Pandey S, Rao VJ, Sreedhar D, Ligade VS, Udupa N. Challenges and opportunities in pharmaceutical sector. Internet $\mathbf{J}$ Third World Med. 2008;7(1).

18. Aggarwal KK. Generic drugs vs patented drugs vs branded drugs vs generic names of the drugs. Available at: http:// www.blog.kkaggarwal.com/2013/02/generic-drugsvspatented-drugs-vs-brandeddrugs-vs-generic-namesof-thedrugs. Accessed 9 August 2017.

Cite this article as: Mohith N, Nalini GK, Deepak P, Sahana GN, Nagaral JV, Rakshitha BV, et al. Analysis of cost between branded medicines and generic medicines in a tertiary care hospital. Int $\mathbf{J}$ Basic Clin Pharmacol 2019;8:1074-7. 